\title{
Desenvolvimento rima com encantamento
}

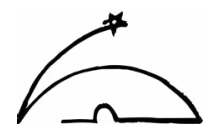

\author{
Alcida Rita Ramos ${ }^{l}$
}

Dá-me um fio de teu cabelo e te direi quem és

Perrot, Rist e Sabelli 1992, p.11

\section{Resumo}

Ao trabalhar o tema do desenvolvimento e da interculturalidade, a antropologia, com sua experiência centenária de tentar compreender mundos não ocidentais, tem a obrigação de 1) questionar a validade universal de expressões como essas, principalmente, quando se transformam em produtos de exportação e 2) trazer à discussão exemplos não ocidentais que refutem, reduzam, ampliem ou dialoguem com esses conceitos. Este trabalho tem por objetivo apresentar situações extraídas de diversos contextos indígenas com o propósito de a) mostrar o quão inadequada é a definição canônica de desenvolvimento para tratar de experiências indígenas que envolvem recursos e riqueza e b) argumentar que o conceito de interculturalidade só merece esse nome quando promove um ecumenismo de ideias e práticas sobre o bem comum, escapando de modismos e premissas ideológicas nem sempre justas em termos de diversidade étnica. Serão analisados vários casos da região amazônica sobre planejamento territorial, experiências que procurar combinar a lógica da dádiva com a lógica do mercado e outras atividades, digamos, heterodoxas do ponto de vista estritamente ocidental.

Palavras-chave: povos indígenas, desenvolvimento, interculturalidade, ecumenismo.

\section{Abstract}

When focusing on development and interculturality, anthropology, with its century-old experience with trying to understand non-Western worlds, would do well to 1) question the universal validity of such notions, especially when they become export products, and 2) bring up non-Western cases that refute, reduce, enlarge or dialogue with them. It examines various indigenous situations a) to show the inadequacy of the canonical definition of development when applied to indigenous experiences involving resources and wealth; b) to argue that the concept of interculturality is worthy of its name when it promotes an ecumenism of ideas and practices about the common good. It avoids fads and ideological premises that are often unfair to ethnic diversity. It examines several cases in Amazonia regarding territorial planning, actions that attempt to combine the logic of the gift and that of the market, as well as other, let us say, heterogeneous activities from the strictly Western point of view.

Keywords: indigenous peoples, development, interculturality, ecumenism.

1 Professora titular emérita da Universidade de Brasília. 
A antropologia, com sua experiência já centenária de tentar compreender mundos não ocidentais, ao abordar temas como desenvolvimento e interculturalidade, tem o inegável dever não só de questionar a validade universal dessas expressões, principalmente, quando passam a ser produtos de exportação, mas apresentar exemplos não ocidentais que refutem, reduzam, ampliem ou, de preferência, dialoguem com tais noções. O objetivo deste trabalho é, portanto, apresentar situações extraídas de diversos contextos indígenas para mostrar até que ponto a definição canônica de desenvolvimento pode ser inadequada quando se trata de experiências indígenas envolvendo recursos e riquezas. Aplicando as mesmas críticas à noção de desenvolvimento, o artigo também pretende, mesmo que sucintamente, argumentar que o conceito de interculturalidade somente faz justiça a esse nome quando promove um ecumenismo de ideias e práticas sobre o bem comum, escapando de modismos e premissas ideológicas nem sempre justas em termos de diversidade étnica.

A teoria e a prática antropológicas deram à disciplina a incumbência de desafiar o status quo, ao questionar a validade universal de afirmações advindas de uma tradição sumamente etnocêntrica, se não mesmo racista. Desenvolvimento é um dos campos de maior disseminação de ideias recebidas acriticamente numa longa série de gerações desinformadas sobre o mundo indígena, seja por ignorância ou por demonstração de poder. Como convém a uma antropologia honesta, buscamos no próprio mundo indígena antídotos para esses venenos conceituais e ideológicos que fazem do planeta um imenso campo de refugiados culturais sem voz nem voto, reféns dos caprichos do Estado, da Modernidade e do Mercado. Nessa busca etnográfica, encontramos posições indígenas diversas, mas convergentes, como a dos ativistas Myrna Cunningham e Dennis Mairena da Nicarágua:

Um equívoco comum é definir desenvolvimento em termos de crescente produtividade, modernização, tecnologia e acúmulo de riqueza. Esta é vista como a posse e o acúmulo de bens materiais. Tal conceito de desenvolvimento é exógeno para os povos indígenas (CUNNINGHAM E MAIRENA, 2009: 8).

Na ponderação de Gersem Luciano, da etnia Baniwa do noroeste amazônico brasileiro,

[a] questão principal não é aceitar ou negar o modelo atual dos projetos de desenvolvimento impostos pelo Estado, mas transformá-lo naquilo que os povos indígenas contemporâneos querem; não é acabar com o desenvolvimento, mas indigenizá-lo (BANIWA, 2009: 7)².

Na eloquência da boliviana Silvia Rivera Cusicanqui:

2 A indigenização do desenvolvimento tem sido uma expressão relativamente corrente, principalmente, nos estudos chamados pós-modernos. Afasto-me da aplicação do termo por Marshall Sahlins (2000), por exemplo, quando focalizo a atenção nos efeitos dessa indigenização, não no mundo globalizado, como faz Sahlins, mas nas realidades locais como as que apresento aqui. 
[A raiz da força aymara e quechua na Bolívia está em] serem ocupantes milenares de um espaço, tê-lo nomeado, ritualizado e convertido em espaço cultural e produtivo à força de festas, trabalhos comunitários, imaginação cultural e tecnologia própria, tudo isso, apesar do assédio da falácia modernizadora que só tem engendrado pobreza e truncado processos de autonomia e autogestão produtiva e política em vastas áreas do território pátrio (RIVERA CUCICANQUI, 2010: 29).

São três visões distintas do desenvolvimento, mas com um forte denominador comum, ou seja: insensíveis a lógicas indígenas locais, os projetos de desenvolvimento nos moldes ocidentais já trazem no seu bojo o próprio fracasso, justamente, por darem as costas às diferenças socioculturais que animam os povos-alvo. Isto torna o sucesso da exportação do desenvolvimento uma missão virtualmente impossível e, na grande maioria dos casos, indesejável no seu aspecto globalizante, refratário a inflexões locais. Se um projeto, por mais caro que seja, não dá certo, culpa-se a "resistência à mudança", como se dizia nos anos 1950 e 60, mas nunca a soberba da estrutura vertical de cima para baixo, que gera mal-entendidos incontornáveis e, com frequência, funestos. Como uma profecia autorrealizável, o idioma do desenvolvimento constrói-se em torno de "valores imutáveis", na expressão de Gilbert Rist (1997: 10). No entanto, ainda citando esse autor, "se 'desenvolvimento' for apenas uma palavra útil para a soma das aspirações humanas, podemos logo concluir que ele não existe em lugar nenhum e provavelmente nunca existirá!' (RIST, 1997: 10; ênfase no original). Agregada ao desenvolvimento está a noção de valor e, como tal, adquiriu no Ocidente o status de crença. Não é por acaso que valor, associado ao desenvolvimento e ao aparato linguístico-ideológico que o sustenta, tem sido descrito como a mitologia programada do mundo moderno (PERROT et al., 1992).

Teríamos aqui uma inversão weberiana. Num raciocínio que não deixa de ter o seu viés evolucionista, Max Weber descreveu o longo processo de secularização na Europa como um afastamento do mundo místico, irracional que então reinava. $\mathrm{O}$ que ele chamou de desencantamento do mundo refere-se à crescente descrença em entidades supra-humanas às quais os povos arcaicos apelavam por viverem num suposto vácuo de racionalidade. "Conforme o intelectualismo suprime a crença na magia", diz Weber,

(...) os processos do mundo se tornam desencantados, perdem seu valor mágico e, portanto, simplesmente 'são' ou 'acontecem', mas não significam mais nada. Em consequência, passa a haver uma demanda crescente para que o mundo e o padrão total da vida fiquem sujeitos a outra ordem que tem valor e significado (WEBER, 1978: 506).

Porém, como o próprio Weber admite, certos setores intelectuais, desiludidos com o status quo, afastaram-se do processo de modernização e passaram a venerar a ciência como se ela fosse "o possível criador ou ao menos o profeta da revolução social" (Ibid.: 514). Ora, se um subproduto da ciência e um dos valores mais fortes da modernidade ocidental é a noção de progresso e seu 
par privilegiado, o desenvolvimento, e se esse valor tem a onipotência e omnisciência do absoluto, então estamos diante de um processo de reencantamento do mundo, agora com progresso e desenvolvimento substituindo a velha Religião (com um universal R maiúsculo), embora as religiões (com o específico $\mathrm{r}$ minúsculo) continuem a vingar tanto na Europa como no resto do mundo. O próprio Weber questiona: "esse processo de desencantamento, realizado ao longo dos milênios da civilização ocidental e, em termos gerais, esse 'progresso' do qual participa a ciência como elemento e motor, tem significação que ultrapasse essa pura prática e essa pura técnica?" (WEBER, 1970: 31). Enfim, o desencantamento weberiano tem sido duramente questionado e agora fala-se claramente do reencantamento do mundo (LANDY E SALER, 2009).

Como então os povos indígenas - que, aliás, já foram rotulados de "hordas fetichistas" pelo positivismo comteano (GAGLIARDI, 1989; SOUZA LIMA, 1995) - reagem a esses complexos processos de desencantamento e reencantamento do mundo dos brancos? Creio que poderíamos afirmar que os brancos nunca se apresentaram aos indígenas como seres desencantados, campeões da razão e do secularismo. Ao contrário, em muitos casos, eles surgem como fontes de desequilíbrio na forma de objetos, palavras e feitos que requerem um intenso trabalho simbólico de depuração antes de entrar no cotidiano indígena, como é fartamente demonstrado em Pacificando o Branco (ALBERT E RAMOS, 2000).

Assim, se a força motriz ocidental repousa no triângulo ciência-progresso-desenvolvimento, ela - como disse Marshall Berman (1986) sobre tudo que é sólido na modernidade - se desmancha no ar ao chegar aos povos indígenas. São eles os desencantados do desenvolvimento, ao experimentar direta ou indiretamente os seus efeitos. Talvez mais do que ninguém, os povos indígenas têm tido o dúbio privilégio de olhar de frente a face monstruosa da quimera do desenvolvimento, ao verem seus recursos naturais serem descaradamente pilhados, seus sistemas de conhecimento vilmente apropriados, sua saúde e bem-estar esmagados por interesses meramente mercantis, sem nenhum compromisso com a lógica e a razão da vida indígena. O desencantamento sobre o mundo dos brancos é uma constante na experiência vivida e pensada pelos povos indígenas desde o século XVI. Os longos milênios da civilização indígena anteriores à invasão europeia do Novo Mundo não os prepararam suficientemente para enfrentar a crença ocidental em seu autoatribuído papel de arauto da verdade divina, que tem como ato de fé o sempiterno progresso. Em nome desse fugidio desenvolvimento, tudo podem, tudo fazem. No entanto, o contexto interétnico é o que mais tem produzido evidências da inoperância de tentativas de desenvolvimento com seus resultados desastrosos: rodovias que rasgam a floresta sem chegar a destino algum, projetos insustentáveis de colonização, hidrelétricas que não produzem energia, monoculturas que levam à fome. Ao mesmo tempo, são oportunidades para desmistificar a crença no desenvolvimento, desnudando seus dogmas, suas seitas, seus seguidores, etc. Neste sentido, os povos indígenas estão na vanguarda da desilusão que, aparentemente paradoxal, mas dialeticamente previsível, já faz parte do próprio projeto desenvolvimentista. Por outro lado, é no campo do desenvolvimento - e, principalmente, do etnodesenvolvimento - que os povos 
indígenas trazem de volta o reencantamento, ao injetar em projetos desenvolvimentistas as suas crenças, as suas profecias, os seus saberes e os seus temores. São eles que estão reencantando aquele mundo dos brancos que os interpenetra.

Com uma dose substancial de ironia, Gilbert Rist assim se refere aos operadores do desenvolvimento (especialistas em economia): "Sua autoridade não depende tanto de resultados como do cuidado que têm em cumprir as suas obrigações" (RIST, 1997: 23), o que soa de maneira inquietante ao dever da desobriga dos padres católicos. Pouco importa a eficácia da missa, o que é preciso é cumprir o preceito quaresmal. Rist, convencido de que o desenvolvimento foi feito para não dar certo, confere-lhe o status de religião para o Ocidente e vai mais longe:

Assim como os cristãos conhecem os inúmeros crimes praticados em nome de sua fé e mesmo assim continuam a apoiá-la, também os especialistas em 'desenvolvimento' cada vez mais reconhecem os erros sem questionar as razões que os levam a se alistar nela. A crença é feita de tal modo que pode facilmente aguentar contradições (RIST, 1997: 23).

\section{Desenvolvimento atinge indígenas da Amazônia}

As quatro situações apresentadas a seguir mostram como "tradição" e "modernidade" passam pelo crivo de construções e desconstruções indígenas no contexto da Amazônia ${ }^{3}$. Há uma série de pontos comuns que perpassam os quatro casos e cada contexto gera respostas próprias dos indígenas envolvidos. Diríamos que são casos paradigmáticos desta nova era do indigenismo ${ }^{4} \mathrm{em}$ que o suposto isolamento dos povos indígenas da Amazônia mostra sua dupla face de romantismo mistificador e de insolência dominadora. A ideologia que se propaga por alguns setores da nação brasileira quer, como dizem os ingleses, comer o bolo e ter o bolo ao mesmo tempo (have your cake and eat it too), ou seja, afastar o "problema indígena" para a recôndita e inacessível floresta amazônica e, ao mesmo tempo, usurpar as terras indígenas em nome de um desenvolvimento fugidio, ilusório e, portanto, inoperante.

3 Esses quatro casos correspondem às áreas que são objeto do projeto de pesquisa "Povos Indígenas, Fronteiras e Políticas Nacionais" financiado pelo Conselho Nacional de Desenvolvimento Científico e Tecnológico (CNPq) do Brasil e dividido em quatro subprojetos: "Os Ashaninka na fronteira Brasil-Peru” a cargo do Dr. José Pimenta, "Os povos Tukano na fronteira colombo-brasileira” do Dr. Luis Cayón, “Os Ye'kuana na fronteira binacional: estratégias e políticas étnicas de transformação" (fronteira Brasil-Venezuela) da Dra. Karenina Andrade, e "O ouro e o outro: políticas públicas e garimpo na Terra Indígena Yanomami” (fronteira Brasil-Venezuela) do Dr. Rogério do Pateo (este último caso foi aqui excluído por não ter relevância direta para o presente trabalho). Com exceção do Alto Rio Negro brasileiro, as análises aqui apresentadas correspondem ao trabalho anterior desses pesquisadores em suas respectivas áreas de atuação.

4 Por indigenismo refiro-me ao amplo fenômeno político que não se limita ao campo das políticas estatais ou privadas sobre a "questão indígena", mas inclui, por exemplo, as imagens do Índio criadas pelos meios de comunicação em massa, pelos trabalhos de ficção, pela atuação de missionários, pelos ativistas dos direitos humanos, pelas análises antropológicas e pelas posições dos próprios índios sobre a construção dessas imagens. Trata-se, pois, de um aparato ideológico sobre as diferenças socioculturais no interior do Estado-nação (RAMOS, 1998: 6-7) e que poderia ser chamado de Orientalismo Americano (RAMOS, 2012), seguindo o exemplo de Orientalism, de Edward Said (1979). 


\section{Reciprocidade devida}

Comecemos com a alentada análise de Gersem Luciano, doutor em antropologia, professor da Universidade Federal do Amazonas e membro da etnia Baniwa da região do Uaupés, no noroeste da Amazônia brasileira. Como numa cápsula, o título de sua dissertação de mestrado já contém o tema e a abordagem do autor: Projeto é como branco trabalha: as lideranças que se virem para aprender e nos ensinar (2006). É a citação-síntese de um indígena da região que denuncia o desequilíbrio de forças contido na noção de projeto de desenvolvimento. $\mathrm{O}$ autor esclarece muitas vezes que não é contra o desenvolvimento, mas aponta firmemente a maneira inadequada como o Estado brasileiro impõe ações e atitudes que pretendem dobrar os indígenas ao molde ocidental de praticar o desenvolvimentismo, ou seja, por um único caminho, "o caminho do mercado" (BANIWA, 2006: 44). Desde que observados os desejos indígenas, Baniwa considera que o desenvolvimento é até mesmo uma necessidade incontornável para os seus compatriotas, depois que sofreram por mais de século a colossal influência de missionários salesianos que os empobreceram culturalmente ao lhes incutir as ideias básicas de uma sociedade que, acima de tudo, crê em progresso e em riqueza material. Nos internatos salesianos, os indígenas do Alto Rio Negro (em sua maioria de fala tukano e aruak) receberam uma educação que, mesmo não sendo laica, foi eficaz em transmitir-lhes conhecimentos sólidos da língua portuguesa e de outros campos do saber. Essa educação - que Baniwa prefere chamar de instrução, pois educação é a transmissão de princípios e valores a cargo da família extensa - submeteu os jovens indígenas a um regime austero e orientado à assimilação. No entanto, por efeito dialético, esse mesmo regime escolar equipou-os com os instrumentos que, mais tarde, lhes foram muito úteis na defesa de sua autonomia e direitos étnicos, como manda a Constituição do país. Porém, há que enfatizar que as escolas salesianas, por mais que tentassem, não formaram "brasileiros genéricos". Ao contrário, acabaram por reforçar o desejo de fortalecer sua especificidade cultural. Hoje os indígenas do Alto Rio Negro são um dos grupos mais bem preparados para enfrentar as vicissitudes do estreito contato com a sociedade regional e, mais amplamente, nacional.

Baniwa expõe "as dificuldades enfrentadas pelos povos indígenas na gestão de projetos e programas resultantes de desencontros entre realidades e racionalidades distintas: entre o entendimento que se tem de políticas de desenvolvimento por parte dos planejadores e os diferentes horizontes socioculturais dos povos indígenas" (BANIWA, 2006: 12). Com admirável lucidez, sua análise vai desenrolando a longa meada desses desencontros que, na maioria das vezes, não são percebidos pelos agentes de desenvolvimento como desencontros em que eles mesmos são parte do problema, mas simplesmente como ignorância ou intransigência dos indígenas. $\mathrm{O}$ foco de sua análise são os projetos de desenvolvimento que começaram a atrair a atenção local a partir das liberdades cidadãs que a Constituição Federal de 1988 garantiu aos povos indígenas 5 . O trabalho

5 A Constituição da República Federativa do Brasil de 1988, chamada Constituição Cidadã, foi promulgada para substituir a anterior, aprovada no regime militar (1964-1985). A nova constituição trouxe aos índios uma série de liberdades, tanto no sentido de garantir seus direitos territoriais e culturais, como jurídicos ao eliminar virtualmente a figura da tutela.

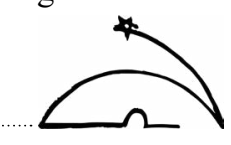


de desconstrução semântica do conceito de projeto é um dos pontos altos do texto. Projeto, que normalmente entendemos como uma virtualidade, ganha corpo na concepção indígena naquela região da Amazônia, mas um corpo com alma indígena: "os projetos etnopolíticos de luta pelos direitos como a terra, saúde, educação e autossustentação fazem parte da estratégia dos índios de apropriação dos instrumentos de poder dos brancos em favor de seus interesses presentes e futuros idealizada e levada a efeito pelas atuais lideranças indígenas" (BANIWA, 2006: 111). Tudo isto parece resultar da convicção indígena de que "projeto" é "troca", mas uma troca muito especial, ao menos do ponto de vista antropológico, como tento esclarecer, recorrendo ao acervo mitológico do Alto Rio Negro e alhures no mundo indígena sul-americano.

Era uma vez um demiurgo e o seu povo escolhido. Ao fundar o mundo social, o demiurgo apresenta ao povo escolhido a oportunidade de adotar uma série de bens que formariam a sua base material: arcos, flechas, canoas, redes, panelas de barro, de um lado; espingardas, rádios, aviões, utensílios de metal, do outro. Para surpresa do demiurgo, o povo escolhido, sem saber que dose de poder acompanhava cada série, optou pela primeira, enquanto a segunda, como que de sobra, foi dada a outro povo, os brancos. Hoje, cientes do poder que aquela parafernália rejeitada conferiu aos brancos, os povos indígenas do Alto Rio Negro consideram que seu despojamento mítico foi uma dádiva que eles mesmos deram aos brancos naqueles tempos primordiais e que agora, os "projetos" que os brancos lhes trazem são nada menos que o esperado ato de reciprocidade há muito devido. Portanto, quando críticos apontam o caráter "paternalista" e "clientelista" da maioria dos projetos de desenvolvimento em terras indígenas, eles não conhecem ou não levam em conta essa versão própria dos índios. Para os Baniwa,

\footnotetext{
(...) essas noções não se aplicam, uma vez que entendem esse tipo de relação como nada mais do que dever e obrigação dos chefes brancos, na lógica da reciprocidade e do caráter distributivo de bens e serviços que caracteriza a cultura baniwa, na qual a contrapartida dos índios é a própria causa indígena, o voto que elege os chefes políticos e a dádiva concedida pelos deuses baniwa, desde a origem do mundo, para que os brancos fossem tecnicamente mais fortes (Baniwa, 2006: 125).
}

Além disso, projeto "é traduzido como trabalho e desenvolvimento como melhoria de vida" (Ibid.: 125). Nos projetos os indígenas ativam sua resiliência ao conseguir reverter as estratégias dos próprios brancos em favor da continuidade étnica, não mais guiadas por antigas interpretações da ordem mítica, mas a partir de novas reinterpretações, incorporando as inovações cosmológicas e cognitivas trazidos pelos brancos. "O projeto só é viável se nós não perdermos o controle social sobre o processo" (Ibid.: 12). Os projetos, portanto, seriam mecanismos de alcançar um nível de vida satisfatório no presente, mais do que no futuro, ou seja, seu horizonte é o curto prazo, não a utopia. Sua noção de realização humana não está no acúmulo de riqueza, mas no bem-viver do presente. 
Esta noção implica uma outra que é muito característica dos povos indígenas, em especial, na Amazônia. Refiro-me aos riscos da acumulação de riqueza. É corrente na literatura antropológica da região o registro da generosidade como uma das virtudes superiores de dada sociedade. Acumular bens atrai a atenção da comunidade que reage através de vários mecanismos de rejeição à pessoa que acumula. Um desses mecanismos é a feitiçaria ou a acusação de feitiçaria, que levaria a vítima à desgraça, se não à morte. Não é diferente no caso do Alto Rio Negro, onde os empreendedores locais, coordenadores de projetos, em especial, se tornam perigosamente vulneráveis, pois são vistos como gestores de grandes somas de dinheiro, dinheiro esse que é visto como pessoal e não comunitário. A conexão entre os recursos que entram nas aldeias e os resultados de sua aplicação sofre muitas mediações financeiras e burocráticas que escapam à grande maioria dos residentes. A desconfiança que disso resulta pode levar ao temor de envenenamento por parte dos administradores indígenas dos projetos, como relata um interlocutor de Gersem Baniwa: "a gente consegue as coisas e tem alguns parentes que acham que você está andando fácil [com motor], ganhando fácil, trazem essas ideias junto com outras coisas, com ameaças de feitiçaria, envenenamento" (BANIWA, 2006: 135). Essa desigualdade econômica é um dos resultados mais dramáticos da entrada de recursos desproporcionais à vida normal das aldeias por via de projetos de desenvolvimento. Em vista disso, muitos jovens se recusam a administrar projetos. Na raiz desses problemas está a incompatibilidade de horizontes, em que os indígenas acumulam para redistribuir entre si, enquanto os brancos acumulam para alimentar o mercado e suas próprias contas bancárias. Acusações de feitiçaria, um tema clássico da antropologia, passa a ser uma eficaz máquina antidesigualdade, um recurso preventivo contra a exploração de parentes por parentes (RIVIÈRE, 1970). Para agravar ainda mais esse dilema, temos o problema de disputas por poder. "Os projetos, independentemente de seus resultados efetivos, acabam quase sempre criando sérios conflitos nas comunidades que geralmente não são considerados no âmbito dos planejamentos e das avaliações técnicas, na medida em que os índios nunca os revelam por força da tradição, para não aprofundar os conflitos internos” (BANIWA, 2006: 134).

Nem mesmo o propalado desenvolvimento sustentável dá credibilidade ao credo do desenvolvimento, pois "mesmo tendo ampliado sua matriz conceitual para incorporar a dimensão ambiental, pecou por incorporar pouco ou quase nada da dimensão cultural dos grupos sociais [...]. Na prática, a noção de sustentabilidade tem sido apropriada e manipulada pelos países centrais como forma de manutenção de seus interesses políticos e econômicos através de intervenções" (Ibid.: 48). Mas, apesar de tudo, Baniwa crê na plausibilidade de tais projetos, desde que se explicite a "contradição existente entre o discurso e a prática dos projetos, que precisam ser contemporizados em termos de linguagem, conceitos e metodologias para, como dizem os índios, ‘definir se os projetos são ou não são nossos, estão ou não estão a nosso serviço'” (Ibid.: 136). 


\section{A cura do mundo}

Do lado colombiano da fronteira com o Brasil, ainda na região do Uaupés, vivem povos indígenas de diversas famílias linguísticas, com destaque para os Makuna, falantes de língua Tukano. Baseio-me no trabalho de Luis Cayón (2012) para tecer uma série de considerações sobre o impacto e a crítica ao desenvolvimento pelos indígenas e seus modos próprios de lidar com ele, contornar as dificuldades que têm sobre ele e os modos de interação com os agentes brancos do desenvolvimento. Cito extensamente o artigo de Cayón para fazer jus à riqueza de dados e à fineza de interpretação.

Assim como no Brasil, a Constituição colombiana de 1991 marcou profundamente a relação dos indígenas com o Estado e outros agentes do indigenismo naquele país. Um dos efeitos do esforço constituinte - do qual participou um importante líder indígena eleito para o Senado Nacional (MUELAS HURTADO, 2012) - foi a criação das Entidades Territoriais Indígenas (ETIs), que assegura aos índios a propriedade coletiva de suas terras (resguardos), mas delega-lhes diretamente a tarefa de gerenciar seus próprios territórios e fomentar neles o "desenvolvimento" sob a ampla designação de Ordenamento Territorial. Estes planos nada mais são do que

\footnotetext{
Planos de Desenvolvimento Integral ajustados às características de cada povo indígena e que devem ser adotados por seus membros. Este Plano de Desenvolvimento leva em conta os aspectos econômicos, sociais, ambientais, geográficos e políticos, segundo os usos, costumes e cosmovisões de cada povo (RIVERA E GÓMEZ, apud CAYÓN, 2012: 67).
}

Há que ressaltar, porém, que as ETIs, embora criadas pela Constituição de 1991, ainda não foram regulamentadas por legislação ordinária e, portanto, só existem no papel (CAYÓN, 2012: 67). No entanto, independentemente dessa regulamentação, o processo de instalação de projetos de desenvolvimento nos resguardos indígenas continua em vigor e tem levado os índios a um grande esforço de organização, na tentativa de manter sua autonomia territorial e cultural. A esse esforço de conjugar as políticas públicas com as suas próprias, informadas por uma cosmovisão muito distinta da nacional, Cayón chama de cosmopolítica, seguindo a definição de Isabelle Stengers, segundo a qual esse conceito contribui para entender "as articulações de que eventualmente são capazes os mundos múltiplos e divergentes em vista de novos modos possíveis de coexistência, onde estes mundos estão em pé de igualdade" (Ibid.: 66).

Entretanto, o Estado colombiano submete as ETIs à Lei Orgânica de Ordenamento Territorial e quaisquer ações por parte dos indígenas devem estar "em harmonia com o Plano Nacional de Desenvolvimento" (ROJAS, apud CAYÓN, 2012: 67). Temendo, portanto, que decisões estatais lhes fossem impostas irremediavelmente, os indígenas da região do Uaupés colombiano criaram organizações das quais se destacam as Associações de Autoridades Tradicionais Indígenas e, dentre elas, a Associação de Capitães Indígenas do rio Pirá-Paraná - ACAIPI (CAYÓN, 2012: 66). Surge, então, a figura do Plano de Vida, o projeto indígena de confeccionar um "calendário ecológico 
para reivindicar e negociar sua forma particular de vida frente às políticas de desenvolvimento promovidas pelos agentes do Estado" (Ibid.: 66). Para esses agentes, o ordenamento territorial em áreas indígenas visa incorporar os índios à nação, através de projetos a eles impostos, já que, para merecer a propriedade de seus resguardos, os indígenas seriam obrigados a acatar passivamente esses projetos estatais, numa troca flagrantemente desigual. Portanto, suas associações decidiram elaborar planos próprios de desenvolvimento em suas terras, usando uma linguagem que é inteligível e aceitável aos olhos dos brancos, mas inclui dimensões que somente aos indígenas dizem respeito. Com grande perspicácia, eles souberam calibrar a extensão da capacidade de entendimento por parte dos brancos e ajustaram seus planos de vida às limitações destes. $\mathrm{O}$ calendário ecológico é um dos resultados dessa proeza. Ao invés de se dobrar à vontade intransigente do Estado, os indígenas colombianos tiraram proveito das contradições contidas nas políticas públicas e aproveitaram os interstícios abertos pela norma nacional do ordenamento territorial para "consolidar sua autonomia e recuperar seus espaços tradicionais" (Ibid.: 68). Seus Planos de Vida, de caráter cosmopolítico, baseiam-se no devir histórico de cada povo e no fortalecimento de suas "culturas". A ACAIPI, da qual fazem parte os Makuna, passou a privilegiar o conhecimento tradicional dos xamãs e de outros sábios para desenhar mapas ecológico-culturais onde se localizam recursos naturais e simbólicos, lugares sagrados, etc. "As novidades que trouxe a Associação [...] são permitir que as autoridades tradicionais se encontrem cara a cara, conversem e tomem decisões conjuntas, ao mesmo tempo em que têm um espaço público de reflexão sobre os assuntos interétnicos" (Ibid.: 69). Desse modo, acionam e ressignificam seus próprios conceitos cosmológicos, num tipo de "purificação" à la Latour (1994), para servirem como instrumentos úteis nas negociações com o Estado.

Como parte das contradições dos projetos de nação está a duplicidade com relação à diversidade sociocultural da Colômbia. Se, por um lado, o Estado se reconhece como pluriétnico, por outro, tenta anuviar as diferenças internas com uma política de homogeneização pela via de um multiculturalismo mal aplicado. Num primeiro passo, o Estado se autoatribui o poder de reconhecer quem é ou não objeto de diferenciação étnica. Num segundo passo, sob a capa desse pseudomulticulturalismo, engendra-se uma falsa homogeneidade, que entra em flagrante contradição com o postulado da plurietnicidade garantida na Constituição de 1991. É nesse limbo de incompatibilidade lógica engendrado por um Estado central débil que prosperam os Planos de Vida.

O mapeamento dos territórios indígenas pela ACAIPI, mostrando seus recursos naturais e culturais, está longe de se submeter aos critérios estatais que esperam que o levantamento indígena simplesmente indique "os recursos naturais de seus territórios para ver as potencialidades produtivas que, no futuro, os próprios indígenas deverão gerenciar em suas terras e com isso obterão os recursos para apresentar projetos de desenvolvimento, saúde e educação" (Ibid.: 67). Ao contrário, a ACAIPI insiste em que "seu território está ordenado desde que os demiurgos Aywa lhes entregaram e que a forma de administrá-lo é mediante o conhecimento de 'manejar o 
mundo de outra dimensão para assim obter o bem-estar da natureza e da humanidade"'. O projeto da ACAIPI traz à tona elementos cruciais que não têm merecido qualquer atenção por parte de agentes desenvolvimentistas, muito menos do Estado, apesar de este ter firmado seu compromisso com a diversidade cultural.

[O]s sítios sagrados têm uns donos sobrenaturais com quem os kumua (xamãs) se comunicam, e [...] a boa comunicação entre eles mantem a ordem dentro do território. Se se desrespeita os donos e os lugares, surgem doenças e problemas, e, por isso, se opõem veementemente às possibilidades de realizar explorações minerais em seu território (Ibid.: 70-71).

O calendário ecológico é outro aspecto dos Planos de Vida que encerra uma imensa complexidade cosmológica, envolvendo cantos, danças, visões alucinógenas vinculadas a atividades sazonais, sempre acompanhadas da necessidade de cura xamânica para manter o fluxo da vida em todas as suas dimensões. Um exemplo do encadeamento no conhecimento ecológico dos indígenas é assim descrito por Cayón:

(...) sabem que depois da frutificação da pupunha (Bactris gasipaes), quando as Plêiades se aproximam do zênite, vem uma última piracema que indica o início da estação chuvosa, cujo momento inicial faz com que as rãs comestíveis üma cantem durante uma noite inteira, e isso indica que as frutas silvestres estão prontas para ser colhidas e que os humanos podem planejar uma de suas cerimônias com as flautas de yuruparí. Todos esses conhecimentos "ecológicos", junto aos saberes minuciosos que têm sobre os lugares e os seres não humanos (comportamento, relações simbióticas, hábitos reprodutivos, alimentação, etc.) estão codificados nas fórmulas poéticas próprias da linguagem erudita dos kumua (Ibid.: 71).

Cientes da incapacidade que têm os agentes do desenvolvimento para entender tamanha sofisticação, os indígenas do Uaupés colombiano esforçam-se por simplificar ao máximo a linguagem que utilizam nas suas práticas cosmopolíticas a bem da inteligibilidade. Para isso, alternam seus conceitos próprios com aqueles advindos de especialidades ocidentais, como da geologia e da ecologia. Assim, conseguem satisfazer os agentes do desenvolvimento com seus mapas detalhados e realçar suas posições para um desenvolvimento futuro, em seus próprios termos. Além disso, os Planos de Vida constituem um sistema de tradução, ajustando a sua complexidade cultural à capacidade limitada de entendimento dos brancos. Como aponta Cayón, "os usos de conceitos cosmológicos traduzidos, e às vezes essencializados para um observador externo, transformam-se numa ponte de inteligibilidade indispensável para negociar realidades diferentes" (Ibid.: 74). E conclui:

Na hora da verdade, com conceitos como 'manejo do mundo' ou 'calendário ecológico cultural', estes indígenas criam um espaço onde refletem, contestam e reagem à visão impositiva 
dos agentes e das instituições estatais que tiveram que aceitar [...]. Com isso, os indígenas têm o comando sobre a quantidade de informação necessária e suficiente para ser entendida por seu interlocutor, ao mesmo tempo que tentam salvaguardar-se daqueles momentos em que os técnicos do Estado [...] analisam suas propostas de Planos de Vida (Ibid.: 74).

É possível que o Uaupés colombiano represente um dos exemplos mais brilhantes da indigenização do desenvolvimento.

\section{O conflito de lógicas econômicas}

O terceiro caso que abordo envolve o povo Ashaninka da fronteira Brasil-Peru, em especial, os habitantes do rio Amônia, no lado brasileiro. A análise deste caso foi desenvolvida pelo antropólogo José Pimenta da Universidade de Brasília e abarca mais de um século do contato interétnico desse povo, especialmente, a partir das invasões de madeireiros na região amazônica do Alto Juruá.

Povo de fala aruak, os Ashaninka brasileiros, a partir da segunda metade do século XX, passaram por transformações drásticas em seus modos de vida (Pimenta, 2002). Como resposta às invasões de madeireiros, esse povo deixou seu modo tradicional de assentamento em famílias nucleares dispersas ao longo dos rios para se reorganizar numa só comunidade, Apiwtxa, concentrada no extremo nordeste de seu território, de modo a fiscalizar a entrada de estranhos pelos rios brasileiros (Pimenta, 2006). Para isso, contaram com o forte estímulo social e financeiro de agentes da FUNAI. Em Apiwtxa, está reunido o maior número de Ashaninka do lado brasileiro.

O processo de unificação social e reorganização econômica dos Ashaninka traz-nos uma situação analiticamente fértil, que poderíamos chamar de caso-limite, no que concerne às contradições que os indígenas enfrentam em sua luta por autonomia étnica e independência econômica. Esses indígenas viram-se frente ao dilema de ou manter seu estilo de vida tradicional e serem destruídos pelos invasores, ou adotar um novo padrão como forma de se livrar deles. O encadeamento de ações que esse processo de mudança acarretou tem trazido à vida dos Ashaninka elementos novos que os surpreendem e preocupam, como o embate entre a lógica da dádiva e a lógica do mercado.

Uma série de fatores externos às suas tradições - o extraordinário empenho de agentes da FUNAI, o casamento de um grande líder com uma mulher branca da região - foram decisivos para deflagrar essa grande transformação na vida dos Ashaninka do Amônia (Pimenta, 2002; 2006; 2008), a começar pela mudança no sistema político. Com a criação de uma única comunidade, a autoridade difusa dos cabeças de família foi substituída pela figura de um líder mais centralizador, cuja influência afeta a todos os cerca de 300 habitantes da aldeia de Apiwtxa. Esse líder, já reconhecido como tal antes das mudanças, assumiu o papel de coordenador das ações que levaram à expulsão dos invasores e à reorganização da vida comunitária. A terra foi legalmente 
demarcada e restava agora buscar meios de manter a comunidade autônoma e economicamente autossuficiente. Criaram nos anos 1990 uma associação com status de pessoa jurídica e que leva o nome da aldeia. Vieram então os projetos: projeto de cooperativa, projeto de escola, projeto agroflorestal, etc. Depois da instituição da chefia, da instalação da "comunidade" e da criação da associação, o próximo passo em direção à nova configuração socioeconômica foi a inauguração da cooperativa, também nos anos 1990. Desse modo, tentaram "participar da economia de mercado e assegurar, ao mesmo tempo, sua reprodução física e cultural como povo indígena diferenciado" (PIMENTA, 2006: 3). Para o propósito desta discussão, a cooperativa é especialmente importante.

Recursos advindos de um projeto permitiram a criação da cooperativa com a aquisição dos bens industrializados necessários para o pagamento aos indígenas que fornecessem, primeiro, produtos agrícolas e, depois que essa alternativa se mostrou inviável, de artesanato para alimentar o mercado externo do exotismo. A cargo da cooperativa estão vários dos filhos do casal interétnico conhecidos como a família Pianko. Com conhecimento suficiente sobre o mundo dos brancos, eles gerenciam a cooperativa dentro dos moldes requeridos pela lógica do mercado, ou seja, recebe pagamento quem trouxer artesanato para vender na cooperativa.

Numa tentativa de amenizar o caráter mercantil da cooperativa, esta foi recentemente nomeada como ayompari, que designa o sistema tradicional de trocas dos Ashaninka e que eles próprios traduzem como 'meu amigo', 'meu parceiro de troca' (Id., 2008: 140). No entanto, a questão é muito mais complexa do que a mera atribuição de um nome. O sistema mercantil que rege a cooperativa e que é tão zelosamente preservado por seus administradores gera grande descontentamento entre os membros da comunidade, que começam a se queixar do que veem como intransigência dos gestores e vantagens que os beneficiam, no que Pimenta chama de "uma posição estrutural" advinda do "sistema cooperativista de commodities" (Id., 2006: 28). Numa cadeia de acontecimentos - criação de chefia, sedentarização em comunidade, instalação de cooperativa vemos o caminho praticamente inexorável para a formação de um capitalismo embrionário onde desponta, clara e consistentemente, a desigualdade social (Pimenta, 2008). Poderíamos então dizer, parafraseando Durkheim sobre o fenômeno religioso, que o caso Ashaninka é um exemplo das "formas elementares do sistema capitalista".

Um contraexemplo pode esclarecer esse caminho de maneira mais dramática. Kishare, um líder Ashaninka nos moldes tradicionais, para quem a generosidade era um atributo fundamental no exercício da autoridade que atrai seguidores, vendo o sucesso dos Pianko com a sua cooperativa, decidiu criar a sua na própria aldeia, fora dos limites de Apiwtxa. Conseguiu os recursos iniciais para suprir a cooperativa de artigos de troca e passou a distribuí-los ao sabor dos pedidos de seus corresidentes, sem receber a contrapartida em artesanato ou outros bens produzidos pelos índios. A generosidade de Kishare, que tanto agradou a seus parentes, foi vista pelos brancos como um ato de desperdício e, por isso, não supriram mais a sua cooperativa que, previsivelmente, deixou de existir. O resultado foi que sua gente o abandonou e a aldeia ficou vazia. A (má) sorte de Kishare não poderia ser mais demonstrativa da incompatibilidade entre dádiva e mercado. "Kishare se 
isolou socialmente e se refugiou na floresta onde passava dias e noites, sozinho, conversando com animais. Abandonado por seus seguidores [...] Kishare perdeu a vontade de viver, parou de alimentar-se, adoeceu e deixou-se morrer" (Ibid.: 12).

Enquanto isso, comandados pela família Pianko, os residentes de Apiwtxa embarcavam em diversos projetos de desenvolvimento sustentável, uns abandonados, outros em suspenso e outros ainda com muito sucesso. $\mathrm{O}$ mais conhecido desses projetos refere-se à comercialização de sabonetes artesanais, que lhes custou grandes transtornos com parceiros comerciais, devido à quebra de direitos sobre recursos naturais e conhecimentos tradicionais associados (Id., 2004; PIMENTA E MOURA, 2010). Uma das grandes ambições dos Ashaninka do rio Amônia é difundir entre os indígenas e não indígenas da região a necessidade de preservar a floresta e buscar alternativas sustentáveis de sustento. Por tudo isso, os Ashaninka passaram a incorporar o arquétipo - tão caro aos ideólogos da sustentabilidade - de "índios ecológicos" por excelência (PIMENTA, 2007: 633). Esse é o nicho ideológico que, equivocado ou não, parece estar mais próximo de fazer justiça ao estilo indígena de viver.

\section{Empreendedorismo ascético}

No extremo norte do Brasil, na fronteira com a Venezuela, vive o povo Ye'kuana, também conhecido na literatura etnográfica como Makiritare ou Maiongong. Falantes de língua Caribe, os Yek'uana são mais numerosos na Venezuela; no Brasil, contam com cerca de 400 pessoas divididas em quatro aldeias ao longo dos rios Auaris e Uraricoera, no estado de Roraima. Diferentemente da maioria dos povos indígenas hoje, os Ye'kuana do Brasil não são pressionados pela cobiça forasteira por suas terras, embora, até o fim do século XIX, tivessem sofrido os horrores da exploração da borracha na bacia amazônica (ANDRADE, 2007). Seus vizinhos imediatos são os Sanumá, com quem se engajaram em diversas escaramuças no século $\mathrm{XX}$, até estes últimos se instalarem definitivamente no vale do rio Auaris (RAMOS, 1980). O caso Ye'kuana foi descrito por Karenina Vieira Andrade, professora de antropologia da Universidade Federal de Minas Gerais.

Uma das características mais marcantes dos Ye'kuana brasileiros é o seu sentido de independência. Ao contrário dos demais indígenas de Roraima, nunca se afiliaram à organização mais forte do estado, o Conselho Indígena de Roraima (CIR), tendo, recentemente, criado a sua própria associação. Antes da derrocada do ciclo da borracha, eram os líderes de uma gigantesca rede de trocas envolvendo um grande número de povos indígenas (e mais tarde, os próprios invasores brancos) na região do Maciço das Guianas, mais especificamente, no Alto Orinoco (ARVELO-JIMÉNEZ, 2001; ARVELO-JIMÉNEZ E BIORD, 1994; ARVELO-JIMÉNEZ et al., 1989). Atualmente, suas aldeias em solo brasileiro fazem parte da Terra Indígena Yanomami demarcada oficialmente em 1991, em meio à maior invasão de garimpeiros na história daquela região.

Ao contrário dos casos relatados acima, os Ye'kuana não aderiram de corpo e alma ao mercado de projetos e suas realizações se devem, principalmente, ao seu próprio esforço, seguindo 
os ditames de seu próprio projeto de vida, sem fazer concessões a doadores. Assim como seus vizinhos Sanumá, os Ye'kuana não sofrem pressões de posseiros nem outros agentes de colonização. O Estado brasileiro faz-se presente através de um pelotão de fronteira, um posto da FUNAI e um posto de saúde. Com as frequentes expulsões de várias ondas de garimpeiros, a Terra Indígena permanece livre de colonizadores permanentes, o que dá a esses povos indígenas a rara oportunidade de decidir quando e como querem manter contato com forasteiros.

O já proverbial senso de empreendedorismo Ye'kuana (ANDRADE, 2007; 2009) está diretamente ligado à sua visão do mundo, que tem a forma de uma profecia. Conhecidos e admirados regionalmente como índios confiáveis, que trabalham bem, os Ye'kuana esmeram-se em manter a qualidade de seus produtos, seja artesanato ou farinha de mandioca, graças à "sua ética ascética do trabalho permanente, incessante" (Id., 2009: 142). Essa ética é alimentada por uma profecia que faz parte do código moral ye'kuana conhecido como wätunnä. Todas as normas do comportamento apropriado, toda a história do povo ye'kuana e todo o porvir estão contidos nesse código. A profecia inscrita em wätunnä evoca a crença em ciclos sucessivos do mundo. Já houve outros no passado e o atual, sob o poder dos brancos, não durará por muito mais tempo, já havendo mesmo sinais claros do seu fim. Os Ye'kuana, certos de que no próximo ciclo serão eles os donos do poder, precisam preparar-se com o máximo possível de conhecimento para não cometer os erros dos brancos, enfurecer o demiurgo e trazer de volta o horror de outro fim de mundo. Essa preparação envolve um intenso e extenso aprendizado do mundo: desde aprender com os animais, com os outros povos vizinhos com quem conviviam em sua grande rede de trocas, até a escola dos brancos. O paradoxo da profecia é que o próprio processo de acumular conhecimento, especialmente dos brancos, já vai levando os Ye'kuana ao desaparecimento, pois vão ficando cada vez mais semelhantes aos brancos ao irem perdendo suas características próprias.

Nesse processo plenamente autônomo, os Ye'kuana forjaram uma ética de trabalho e de empreendedorismo que os torna um caso único na etnografia da Amazônia. Em 1990, um incidente trágico na aldeia à beira do Olomai, afluente do rio Auaris em Roraima, que deixou dois Ye'kuana e três garimpeiros mortos e alguns Sanumá feridos, exemplifica essa especificidade Ye'kuana. O motivo foi o desaparecimento de dois quilos e trezentos gramas de ouro em poder dos garimpeiros. Esse incidente serviu para mostrar os contrastes entre os principais agentes na corrida do ouro na Terra Indígena Yanomami, na virada dos anos 1980. Essa situação extrema de desencontros culturais entre dois povos indígenas, garimpeiros desprovidos e empresários inescrupulosos pode caber numa cápsula: no bojo do tiroteio que matou o líder Ye'kuana do Olomai, "encontramos o modo Sanumá de adquirir [bens] para distribuir, o modo garimpeiro de acumular para dissipar, o modo empresarial de acumular para reinvestir e ostentar, e o modo Maiongong [Ye'kuana] de acumular para racionalizar" (RAMOS, 1996: 146). O fascínio que os bens industrializados exercem nos Sanumá não tem outra razão de ser que o dever de incrementar e ampliar suas redes de relações sociais. A busca desesperada dos garimpeiros por um veio de 
ouro está ligada ao desejo de esbanjar a riqueza o mais rápido possível para que a sorte continue a acompanhá-los (CLEARY, 1992; MACMILLAN, 1995). O descaso dos empresários, donos de cantinas e aviões a serviço do garimpo, pela perda de peões ou pilotos faz parte de sua ambição de enriquecer rapidamente para investir mais e exibir mais riqueza. Já os Ye'kuana tiveram no auge do garimpo a rara oportunidade de acumular conhecimento - a língua portuguesa, o valor do ouro - e dinheiro para o bem comum da sua comunidade e para cumprir a profecia de wätunnä. A trágica experiência no Olomai reafirma a postura dos Ye'kuana perante a vida: "Há que resgatar o conhecimento que está disperso pelos povos estrangeiros, conhecimento que não se tem tradicionalmente e é preciso acumular" (ANDRADE, 2009: 151). A aquisição de bens não é, pois, motivada pelo acúmulo material, mas pela necessidade de aprender com os brancos, a quem devem esses bens. Até mesmo a fase do garimpo foi-lhes útil nesse aprendizado: além da língua portuguesa, uma forma de produção própria e os dividendos gerados através de cobranças de pedágio de aviões e barcos, pagamentos a guias, etc. $\mathrm{O}$ dinheiro gerado nessas transações foi usado para a compra de uma casa na cidade de Boa Vista, onde seus estudantes puderam se hospedar enquanto lá estudavam, de alguns microscópios utilizados na leitura de lâminas de malária que grassava na região, motores de popa, máquinas de costura, máquinas de ralar mandioca, etc. Porém, mais do que os bens materiais, está a meta a ser alcançada, conforme reza o wätunnä:

A ética ye'kuana levou-os - e ainda leva - a investir o dinheiro obtido através do comércio, do garimpo e, mais tarde, do trabalho remunerado, não só no bem-estar da comunidade, mas em instrumentos que possibilitem a aquisição de conhecimento [...] o consumo é o meio para chegar a um fim: preparar-se para o ciclo futuro, profetizado por wätunnä. Como? Adquirindo o poder dos brancos que se manifesta no acúmulo de bens [...] a aquisição de bens e perspectiva de reinar no próximo ciclo pela apropriação do poder dos brancos só é possível com o acúmulo de conhecimento, aliado ao trabalho (ANDRADE, 2009: 153).

Ao contrário dos Ashaninka, nunca criaram uma cooperativa, sempre distribuíram igualmente os bens adquiridos e, em consequência, não entraram no círculo vicioso mercantil que leva à desigualdade social interna. Como em suas tradicionais viagens de longo alcance, o líder da aldeia "cuidaria da partilha das mercadorias" (Ibid.: 137) obtidas, também agora o "resultado do acúmulo de conhecimento e bens adquiridos através do comércio deve ser acessível a todos" (Ibid.: 151).

Depois de tantas vicissitudes históricas com as ondas de assaltos invasores, com o apelo destruidor das mercadorias e, principalmente na Venezuela, com o assédio persistente de missionários, é espantosa a resiliência dos Ye'kuana em sua determinação de não sucumbir ao canto da sereia ocidental e respeitar e praticar a "horizontalidade nas relações interétnicas ao mesmo tempo que evadem a hierarquização vertical num único movimento etnopolítico com métodos idênticos e mecanismos iguais de luta" (ARVELO-JIMÉNEZ, 2001: 19). 
No entanto, um fenômeno inesperado está trazendo dúvidas aos Ye'kuana no Brasil. Trata-se de uma série de suicídios entre os mais jovens de ambos os sexos que, até agora, não têm uma causa ou causas consensuais. Entre si, os Ye'kuana comentam que a responsável por essas tragédias é a escola - de origem exógena - numa clara expressão de conflito de gerações. Jovens imbuídos de novos conhecimentos estariam começando a contestar a autoridade dos mais velhos. Em alguns casos, percebendo a reação negativa destes a certas expectativas ou atividades não indígenas, vendo-se atingidos em sua dignidade, os jovens desafiam seus pais, avós e autoridades locais, cometendo ou ameaçando cometer suicídio. Será este o limite da profecia wätunnä, para além do qual a posição Ye'kuana no novo ciclo do mundo está posta em questão?

\section{Elementos comuns nas visões indígenas sobre desenvolvimento}

Um olhar mais detido sobre os quatro casos apresentados acima revela que há vários traços comuns no que se refere à problemática do desenvolvimento. Embora sem pretender esgotá-los, exponho alguns dos mais evidentes, a saber: o fascínio por bens de consumo; o repúdio à desigualdade; a aceitação limitada do desenvolvimento através da oferta e demanda de projetos; a busca de compatibilização entre a economia da dádiva e a economia do mercado nas brechas do sistema dominante; a busca por autonomia; a observação dos conhecimentos próprios e apropriados, seja a favor ou contra o desenvolvimento; a crítica ao desenvolvimento sustentável por não levar esses conhecimentos suficientemente a sério.

De uma maneira ou de outra, os bens industrializados exercem um fascínio sobre todos os povos aqui abordados. No entanto, não é uma atração que traz consigo uma mudança estrutural de perspectiva na relação de humanos com objetos. De maneira geral, a acumulação indígena de bens de consumo não tem por objetivo a riqueza individual, mas a redistribuição comunitária. A atração, por exemplo, das miçangas nas trocas com os brancos é sempre notável para quem visita os povos indígenas. No entanto, a acumulação é praticamente inexistente, pois o destino dos bens industrializados é espalhar-se por um espaço que vai muito além dos limites de determinada aldeia. Bens industrializados são "domesticados" para obter a condição apropriada de consumo pelos indígenas (ALBERT E RAMOS, 2000), de modo que passem a entrar na corrente habitual dos objetos nas aldeias. Muito apropriadamente, Stephen Hugh-Jones caracteriza a troca indígena como uma espécie de comutador entre dois mundos. "A troca", diz ele, "desempenha um papel-chave nesse circuito [de bens], fornecendo tanto a dobradiça entre duas economias [da dádiva e do mercado] como a porta por onde elas se interpenetram" (HUGH-JONES, 1992: 70).

O princípio estrutural da igualdade econômica é comum a todos os casos aqui apresentados. Ele está em franca contradição com a desigualdade advinda da concentração de riqueza. Quando esta se torna evidente, como entre os Ashaninka descritos aqui, começam a surgir desequilíbrios sociais que perturbam a ordem vigente. Este caso, que podemos ver como um contraexemplo, mostra-nos como surgem esses desequilíbrios causados pela concentração de bens numa só família, 
ainda que de maneira involuntária. No caso Ashaninka, uma exceção que ilumina a regra, o risco da desigualdade social, conscientemente evitada, é um alerta sobre as contradições entre a economia da dádiva e a economia do mercado; como conviver com ambas no mesmo ambiente social é o grande desafio desse grupo Ashaninka do Brasil. Como vimos no caso Baniwa, a feitiçaria é o antídoto contra o consumismo individual. Gestores de projetos que, em decorrência de suas funções, acabam usufruindo de bens que não estão ao alcance da maioria, sentem a pressão igualitária ao temer os efeitos da feitiçaria contra eles. Já os Ye’kuana agarram-se, como a uma âncora, aos princípios ancestrais da ética do trabalho ascético que os protege da contaminação do individualismo consumista. Não há entre eles queixas de desigualdade social nem de ataques de feitiçaria, talvez porque todos os membros de suas comunidades no Brasil partilham da mesma doutrina ancestral que prevê a morte e o ressurgimento dos Ye'kuana como os próximos donos do poder no mundo.

Em todos os casos aqui apresentados que, muito possivelmente, não destoam da maioria dos povos indígenas da Amazônia, não há uma rejeição sumária do desenvolvimento, mas sim o esforço de moldá-lo ao seu próprio estilo de vida. Desde o final do século XX, o "mercado de projetos" (ALBERT, 2000: 198) vem recobrindo a Amazônia indígena com somas consideráveis de recursos destinados, principalmente, a atividades econômicas. No entanto, a lógica dos projetos choca-se com o modo de vida indígena, quando novas formas de trabalho, de associação e de relações sociais desiguais são impostas aos indígenas, levando, frequentemente, ao fracasso dos empreendimentos. Gersem Baniwa discorre amplamente sobre as contradições que os projetos impingem às comunidades, justamente, porque os "donos dos projetos", ou seja, os doadores dos recursos, desconhecem ou desconsideram aspectos da vida indígena que contemplam planos da realidade que vão muito além da mera transação comercial. Restrições a certas formas de trabalho, interação entre humanos e não humanos, obrigações incontornáveis de parentesco etc., prioritárias para os indígenas, são, muitas vezes, interpretadas como malversação no uso de recursos financeiros, favoritismo nepotista, desperdício ou simples ignorância ou ingenuidade no manejo do dinheiro e da burocracia. Esse conflito de interpretações responde por uma boa parte dos projetos fracassados. Há que destacar a atitude dos Makuna e seus vizinhos no Uaupés colombiano que, prevendo tais mal-entendidos, souberam dosar seus conhecimentos próprios à capacidade de compreensão dos brancos. Assim, o que estes poderiam rotular de superstições e crendices, os Makuna fazem-nos ler sabedoria ecológica. No entanto, o Estado continuamente produz novos mal-entendidos casuísticos, sobrecarregando cada vez mais os esforços indígenas de chegar à compreensão mútua (CAYÓN, 2013: 127-128). Também aqui os Ye'kuana fogem à regra e se recusam a entrar no mercado de projetos, principalmente, para fins econômicos. Têm obtido pequenos recursos para a compra de rádios que ajudam na fiscalização do território indígena e para a revitalização de cerimônias há muito desativadas. No entanto, no que toca à possibilidade de se tornar dependentes de recursos e consultores externos, a parcimônia ye'kuana tem-lhes garantido um alto grau de autonomia pouco comum na Amazônia. Comerciantes tradicionais por 
excelência, esses argonautas da Amazônia usam racionalmente sua experiência histórica com a dependência para agora saber evitá-la.

\section{Os equívocos da sustentabilidade e da interculturalidade}

Sobre o conteúdo cultural do conhecimento, devo insistir no aspecto indivisível do legado cultural. Na noção mesma de territorialidade, está um universo repleto de crenças, relações sociais e conhecimento prático que integra uma dada sociedade. Este ponto aparece repetidamente nos casos descritos acima e, na verdade, por gente nativa do mundo inteiro. Por isso, o conhecimento indígena não pode transferir-se mecanicamente de um tipo de sociedade a outro, como se se tratasse de uma transfusão mental. O que provavelmente ignora a gente de negócios, que mostra admiração pela forma sustentável com que os indígenas utilizam seus recursos, é que essa sabedoria envolve algo mais do que a simples identificação, descrição e utilização da fauna e da flora. Esse conhecimento está ligado a cosmologias e estilos de vida tão diferentes da forma de vida ocidental que são não apenas indetectáveis, mas totalmente desconcertantes e praticamente incompatíveis com a vocação predatória das atividades industriais. O que muitas vezes se vê como costumes estranhos - proibições alimentares, restrições extranaturais à caça, pesca etc., divisão de trabalho motivada por razões metafísicas, elaboração de rituais de preferência a atividades econômicas - pode ser a pedra angular do conhecimento indígena. Os negócios, pragmáticos por definição, não conseguem harmonizar-se nem se encaixar às particularidades culturais da vida nativa, o que nos leva a questionar se as demonstrações de respeito pela sabedoria indígena não são meras formalidades para satisfazer ao politicamente correto (RAMOS, 2006: 257).

Temos o exemplo do conceito tão problemático de espiritualidade. Não passa pela barreira da racionalidade e objetividade ocidentais, mas é, de fato, uma peça-chave para compreender o diversificado universo indígena (Id., 2014) ${ }^{6}$. Como observou Darrell Posey, a espiritualidade "é a mais elevada forma de consciência e a consciência espiritual é a mais alta forma de entendimento. Neste sentido, o conhecimento tradicional não é conhecimento local, mas uma expressão do conhecimento universal, expresso através do local" (POSEY, 2002: 28). Para o pensador Tewa, Gregory Cajete, espírito e espiritualidade nada têm a ver com religião, mas com a busca de verdade ou verdades: "A ciência nativa, em seus níveis mais altos de expressão, é um sistema de caminhos para chegar a essa verdade perpetuamente em movimento, ou "espírito"' (CAJETE, 2000: 19). A diferença entre linguagem literal e linguagem simbólica passa ao largo da capacidade ocidental de entender a diversidade do pensamento humano. Esta é, sem dúvida, uma grande barreira para o entendimento mútuo sobre o que seria o desenvolvimento e seus derivados.

Em defesa do etnodesenvolvimento, próprio dos "grupos étnicos no interior de sociedades mais amplas", Rodolfo Stavenhagen propôs que ele deve "tornar-se a principal questão da reflexão sobre o desenvolvimento, tanto teórica quanto praticamente” (STAVENHAGEN, 1985: 41). De

6 Ver a excelente demonstração etnográfica de Keith Basso (1996) sobre os Apache ocidentais. 
fato, ao longo dos últimos trinta anos, o desenvolvimento sustentável passou de um desejo a uma realidade, mas apenas na forma de mais uma ideologia da modernidade. Nem Stavenhagen nos anos 1980, nem os defensores atuais do etnodesenvolvimento interrogam o principal, que é o próprio desenvolvimento, ao menos nada semelhante às duras críticas que lhe fazem os integrantes do grupo europeu que, significativamente, leva a sigla M.A.U.S.S. (Movimento Anti-Utilitarista das Ciências Sociais), especialmente, Gilbert Rist (1997) e Dominique Perrot (1991), e um número crescente de autores, como James Ferguson (1994), Arturo Escobar (1995), Stuart Kirsch (2006), Henare (2005), para citar apenas alguns. Rist, por exemplo, afirma que "a ideologia do 'desenvolvimento' entrou no reino do oximoro" (RIST, 1997: 174), esclarecendo que, na literatura ou nos textos místicos, essa figura de retórica permite "dizer o indizível evocando a coincidência de opostos" (Ibid., nota 7). Em suma, desenvolvimento é uma impossibilidade prática. Rist é igualmente cético sobre a noção de desenvolvimento sustentável e, com fina ironia, enquadra-o no famoso dizer de um personagem de Lampedusa: "As pessoas devem ser levadas a pensar que tudo está mudando, de modo que tudo permaneça como era antes” (Ibid.: 182).

Se por etnodesenvolvimento entendermos "o direito de grupos étnicos de participar (ou não [...]) em seus próprios termos do processo moderno de desenvolvimento" (KASSAM, 2002: 65), à luz dos exemplos aqui expostos, não deixamos de dar razão a Rist. "Os próprios termos" dos povos indígenas, quando não entram em conflito direto com a (des)razão desenvolvimentista - temor à feitiçaria, quebra de relações igualitárias -, exigem esforços especiais - malabarismos linguísticos, retraimento social - para não serem atropelados por ela. Da lógica do mercado à lógica científica ocidental, os indígenas acabam por remar contra a corrente consumista para manter sua autonomia e valorizar os próprios conhecimentos. O desenvolvimento sustentável pode até ser bem-sucedido em termos mercadológicos, como com os Ashaninka, mas o custo social talvez seja alto demais para perdurar.

\section{Por fim}

A falácia dedutiva contida na primeira epígrafe deste trabalho demonstra ao mesmo tempo a arrogância de uma certa visão sobre a ciência ocidental contemporânea e sua incapacidade para ultrapassar a empiria superficial. Para além de um fio de cabelo contendo o DNA de alguém, há um universo repleto de modos diversos de ser, de saber e de fazer que até agora se tem mantido refém da ignorância ocidental, apesar de a genética moderna atribuir setenta ou oitenta por cento do comportamento humano, não a genes, mas ao meio-ambiente ou, em termos antropológicos, à cultura. A inapetência ocidental pelo detalhe e pelo esforço de chegar ao entendimento profundo de uma realidade desconhecida, combinada com o desequilíbrio do poder global, tem sido uma das fontes mais daninhas de sofrimento para os povos indígenas. Os efeitos sociais e políticos dessa Méconnaissance, muitas vezes cultivada, podem ser devastadores, como nos mostra Emiko Ohnuki-Tierney em seu sensível estudo 
sobre os pilotos kamikaze na Segunda Guerra Mundial. Méconnaissance, diz a autora, "pode ocorrer quando as partes envolvidas não se dão conta da falta de comunicação" (OHNUKITIERNEY, 2002: 3. Ver RAMOS, 2015).

Subjacente às considerações levantadas aqui com relação ao conhecimento indígena, ao desenvolvimento e às frequentes falhas de entendimento mútuo no mundo interétnico da Amazônia está a noção de interculturalidade. Muito em voga atualmente, em especial, no contexto geopolítico sul-americano, a interculturalidade, por evocar algum tipo de equilíbrio cultural e político, na verdade, pode ser mais uma barreira ao entendimento mútuo. Temo que possa criar mais méconnaissance do que propriamente diálogos equilibrados entre os Estados-nações e os povos indígenas. Uma crítica da interculturalidade apontaria para os lugares estruturalmente distintos dos agentes envolvidos. Para que uma genuína interculturalidade, de fato, se materialize, será preciso que cada parte envolvida tenha igual acesso aos recursos linguísticos, simbólicos e materiais de todas as outras partes. A interculturalidade só fará jus a esse nome quando promover um ecumenismo de ideias e práticas sobre o bem comum, escapando de modismos, premissas ideológicas e promessas políticas que nem sempre são etnicamente apropriadas e justas. Os casos aqui apresentados expõem algumas dessas premissas e apontam para entraves que continuam a fazer do desenvolvimento uma quimera ou, na melhor das hipóteses, uma utopia que, como o próprio nome indica, está fadada a nunca se materializar.

\section{Referências bibliográficas}

ALBERT, Bruce. Associações indígenas e desenvolvimento sustentável na Amazônia brasileira. In: RICARDO, C.

A. (Org.). Povos Indígenas no Brasil 1996-2000. São Paulo: Instituto Socioambiental, 2000, p. 197-207.

e RAMOS, Alcida. Pacificando o branco: Cosmologias do contato no Norte-Amazônico. São Paulo: Unesp, 2000.

ANDRADE, Karenina Vieira. A ética Ye’kuana e o espírito do empreendimento. Tese de doutorado, Departamento de Antropologia, Universidade de Brasília, 2007.

. Wätunnä: Tradição oral e empreendimentos econômicos dentre os Ye'kuana. In: SMILJANIC, M.

I., PIMENTA, J. e BAINES, S. G. (Orgs.). Faces da Indianidade. Curitiba: Nexo Design/Capes, 2009, p. $127-154$.

ARVELO-JIMÉNEZ, Nelly. Movimientos etnopolíticos contemporaneos y sus raices organizacionales en el sistema de interdependencia regional del Orinoco. Série Antropologia, Departamento de Antropologia, Universidade de Brasília, n. 309, 2001. 
, MÉNDEZ, F. Morales y CASTILLO, H. Biord. Repensando la historia del Orinoco. Revista de Antropología (Universidad de los Andes, Colombia), vol. V, n. 1-2, p. 155-174, 1989.

y BIORD, Horacio. The impact of conquest on contemporary indigenous peoples of the Guiana Shield. In: ROOSEVELT, A. (Org.). Amazonian Indians from prehistory to the present. Tucson: University of Arizona Press, 1994, p. 55-78.

BANIWA, Gersem. "Projeto é como branco trabalha; as lideranças que se virem para aprender e nos ensinar": Experiências dos povos indígenas do alto rio Negro. Dissertação de Mestrado, Departamento de Antropologia, Universidade de Brasília, 2006.

To dominate the system and not to be dominated by it. Poverty in Focus (International Policy Center for Inclusive Growth), n. 17, p. 6-8, 2009.

BASSO, Keith. Wisdom sit in places: Landscape and language among the Western Apache. Albuquerque: University of New Mexico Press, 1996.

BERMAN, Marshall. Tudo que é sólido se desmancha no ar. São Paulo: Companhia das Letras, 1986.

CAJETE, Gregory. Native science: Natural laws of interdependence. Santa Fé, NM: Clear Light, 2000.

CAYÓN, Luis. Plans de vie et gestion du monde: Cosmopolitique autochtone du développement en Amazonie colombienne. Recherches Amérindiennes au Québec, vol. XLII, n. 2-3, p. 63-77, 2012.

Pienso, luego creo. La teoría makuna del mundo. Bogotá: Instituto Colombiano de Antropología e Historia, 2013.

CLEARY, David. A garimpagem de ouro na Amazônia. Uma abordagem antropológica. Rio de Janeiro: UFRJ, 1992.

CUNNINGHAM, Myrna y MAIRENA, Dennis. Laman Laka: If I have it you have it, if you have it I have it. Poverty in Focus (International Policy Center for Inclusive Growth), n. 17, p. 8-9, 2009.

ESCOBAR, Arturo. Encoutering development: The making and unmaking of the Third World. Princeton: Princeton University Press, 1995.

FERGUSON, James. The anti-politics machine: “Development," depoliticization, and bureaucratic power in Lesotho. Minneapolis: University of Minnesota Press, 1994. 
GAGLIARDI, José M.. O indígena e a República. São Paulo: Hucitec, 1989.

HENARE, Manuka. The implications of globalization for indigenous communities of New Zealand - Aotearoa and elsewhere - A step towards Te Ao Mārama or towards Te Pō? In: PATMAN, R y RUDD, C. (Org.). Sovereignty under siege?: Globalization and New Zealand. Hants, Inglaterra: Ashgate, 2005, p. 111-128.

HUGH-JONES, Stephen. Yesterday's luxuries, tomorrow's necessities: Business and barter in northwest Amazonia. In: HUMPHREY, C. y HUGH-JONES, S. (Org.). Barter, exchange and value: An anthropological approach. Cambridge: Cambridge University Press, 1992, p. 42-74.

KASSAM, Aneesa. Ethnotheory, ethnopraxis: Ethnodevelopment in the Oromia regional state of Ethiopia. In: SILLITOE, P., BICKER, A. y POTTIER, J. (Org.). Participating in development: Approaches to indigenous knowledge. Londres: Routledge, 2002, p. 64-81.

KIRSCH, Stuart. Reverse anthropology: Indigenous analysis of social and environmental relations in New Guinea. Stanford: Stanford University Press, 2006.

LANDY, Joshua y SALER, Michael. The re-enchantment of the world: Secular magic in a rational age. Stanford: Stanford University Press, 2009.

LATOUR, Bruno. Jamais fomos modernos. Rio de Janeiro: Editora 34, 1994.

MACMILLAN, Gordon. At the end of the rainbow? Gold, land and people in the Brazilian Amazon. Londres: Earthscan, 1995.

MUELAS HURTADO, Lorenzo. Os povos indígenas e a Constituição da Colômbia. In: RAMOS, Alcida R. (Org.). Constituições nacionais e povos indígenas. Belo Horizonte: Editora UFMG, 2012, p. 36-52.

OHNUKI,-TIERNEY, Emiko. Kamikaze, cherry blossoms, and nationalism. The militarization of aesthetics in Japanese history. Chicago: Chicago University Press, 2002.

PERROT, Dominique. Les empêcheurs de développer en rond. Ethnies (La fiction et la feinte: Développement et peuples autochtones), n. 13, p. 4-11, 1991.

RIST, Gilbert e SABELLI, Fabrizio. La mythologie programmée. L'économie des croyances dans la société moderne. Paris: Presses Universitaires de France, 1992.

PIMENTA, José. "Índio não é todo igual”: A construção ashaninka da história e da política interétnica. Tese de doutorado, Departamento de Antropologia, Universidade de Brasília, 2002. 
. Desenvolvimento sustentável e povos indígenas: os paradoxos de um exemplo amazônico. Anuário Antropológico 2002/2003, p. 115-150, 2004.

Reciprocidade, mercado e desigualdade social entre os Ashaninka do Rio Amônia. Série Antropologia, n. 392, Departamento de Antropologia, Universidade de Brasília, 2006, 34 pp.

Indigenismo e ambientalismo na Amazônia ocidental: A propósito dos Ashaninka do rio Amônia. Revista de Antropologia, vol. 50, n. 2, p. 633-81, 2007.

"Viver em comunidade": O processo de territorialização dos Ashaninka do rio Amônia. Anuário Antropológico/2006, p. 117-150, 2008.

e MOURA, Guilherme Moura. O sabonete da discórdia: Uma controvérsia sobre conhecimentos tradicionais indígenas. In: COELHO DE SOUZA, Marcela e LIMA, E. C. de (Org.). Conhecimento e cultura: Práticas de transformação no mundo indígena. Brasília: Athalaia Gráfica e Editora/Capes, 2010, p. 63-93.

POSEY, Darrell. Upsetting the sacred balance: can the study of indigenous knowledge reflect cosmic connectedness?. In: SILlitOE, P., BICKER, A. y POTTIER, J. (Org.). Participating in development: Approaches to indigenous knowledge. Londres: Routledge, 2002, p. 24-42.

RAMOS, Alcida Rita (Org.). Hierarquia e simbiose: Relações intertribais no Brasil. São Paulo: Hucitec, 1980.

A profecia de um boato: Matando por ouro na área Yanomami. Anuário Antropológico/95, p. 121-150, 1996.

Indigenism. Ethnic politics in Brazil. Madison: University of Wisconsin Press, 1998.

The commodification of the Indian. In: POSEY, D. y BALICK, M. (Org.). Human impacts on Amazonia: The role of traditional ecological knowledge in conservastion and development. Nova York: Columbia University Press, 2006, p. 248-272.

Indigenismo: Um orientalismo Americano. Anuário Antropológico/2011-I, p. 27-48, 2012.

Mentes indígenas y ecúmene antropológico. In: BETRISEY, Débora e MERESON, Silvina (Org.). Antropologías contemporâneas. Saberes, ejercicios y reflexiones. Buenos Aires: Miño y Dávila, 2014, p. 35-55.

Sobre malentendidos interétnicos. Universitas Humanística, v. 80, p. 53-75, 2015. 
RIST, Gilbert. The history of development from Western origins to global faith. Londres: Zed Books, 1997.

RIVERA CUCICANQUI, Silvia. Prefacio: Mirando al pasado para cominar por el presente y el futuro. In:

“Oprimidos pero no vencidos”: Luchas del campesinato Aymara y Qhechwa 1900-1980. La Paz: La Mirada Salvaje, 2010 .

RIVIÈRE, Peter. Factions and exclusions in two South American village systems. In: DOUGLAS, M.. Witchcraft confessions and accusations. Londres: Tavistock, 1970, p. 245-255.

SAHLINS, Marshall. Culture in practice. Nova York: Zone Books, 2000.

SAID, Edward. Orientalism. Nova York: Vintage, 1979.

SOUZA LIMA, Antonio Carlos de. Um grande cerco de paz: Poder tutelar, indianidade e formação do estado no Brasil. Petrópolis: Vozes, 1995.

WEBER, Max. Ciência e política: duas vocações. São Paulo: Cultrix, 1970.

Economy and Society vol. 1. Berkeley: University of California Press, 1978. 